\title{
Cross-channel cooperation: on the collaborative integration of online and offline business models of e-entrepreneurs and traditional SMEs
}

\author{
Tobias Kollmann and Matthias Häsel* \\ E-Business and E-Entrepreneurship Research Group \\ Institute for Computer Science and \\ Business Information Systems (ICB) \\ University of Duisburg-Essen \\ Universitätsstraße 9, 45141 Essen, Germany \\ E-mail: tobias.kollmann@icb.uni-due.de \\ E-mail: matthias.haesel@icb.uni-due.de \\ *Corresponding author
}

\begin{abstract}
Owing to the rapid growth of the internet, the corresponding Net Economy has evolved into an established trade level. It is characterised by numerous entrepreneurial firms equipped with innovative online business models. Also, traditional firms increasingly utilise the internet in order to optimise business processes and reach customer segments. Technological advances and changes in customer behaviour imply that the physical and the electronic trade levels are increasingly used complementarily. In order to be successful on both trade levels, Real and Net Economy firms inevitably need to approach each other. In this article, we argue that for e-entrepreneurs and traditional SMEs, collaborative concepts represent an ideal way of meeting the resulting requirements. Cross-channel cooperation enables firms to integrate online and offline business models without extending themselves beyond their means or competencies. Drawing on market- and resource-based considerations, we examine the rationale behind collaborative cross-channel strategies, propose a classification of cooperation forms and give implications for e-entrepreneurs and managers of traditional SMEs.
\end{abstract}

Keywords: cooperation; channel; internet; business model; e-entrepreneurship.

Reference to this paper should be made as follows: Kollmann, T. and Häsel, M. (2008) 'Cross-channel cooperation: on the collaborative integration of online and offline business models of e-entrepreneurs and traditional SMEs', Int. J. Entrepreneurship and Small Business, Vol. 6, No. 2, pp.212-229.

Biographical notes: Dr. Tobias Kollmann is a University Professor. He received his doctorate in 1997 with a thesis on the acceptance of innovative telecommunication and multimedia systems. Since 1996 his special interests have included e-business, e-commerce and, in particular, the phenomenon of 'virtual marketplaces'. In 1997 he moved into the industry to manage the business field of 'e-Business' at Scout-Holding, a member of the METRO Group, where he intensified the development of virtual marketplaces in the B-to-C area. He was also a founder of autoscout24, the largest used-car electronic trading platform in Europe. In October 2001, he followed a call to the University of Kiel, where he held a professorship for e-business, teaching at the innovative Multimedia Campus Kiel. Since 2005, he has held a professorship for E-Business and E-Entrepreneurship at the University of Duisburg-Essen, Campus Essen, where he focuses particularly on questions of business venturing and business development in the field of the Net Economy. 
Matthias Häsel, MSc, graduated in Computer Science and holds a Master's degree in Multimedia Management. After his graduation from the University of Applied Sciences, Osnabrück, Germany in 2004, he started his postgraduate studies at the University of Kiel/Multimedia Campus Kiel-International Graduate School of Digital Media and Management, with a main focus on e-business, and was awarded the title 'Student of the Year' upon his graduation in 2005. Since then, he has been a Research Associate of the E-Business and EEntrepreneurship Research Group, University of Duisburg-Essen. His research is currently focused on information technology competencies in internet-based ventures, as well as internet-based technologies and emerging business models.

\section{Introduction}

With the dawn of the internet in the last decade of the twentieth century, a structural change in both social and economic spheres was induced. Digital channels have become an integral part of daily life and their influence on the transfer of information has become ubiquitous. Above all, new possibilities have emerged with respect to how enterprises create value. An enterprise can create customer value not only by its physical activities, but also through the electronic level (Weiber and Kollmann, 1998; Amit and Zott, 2001; Lumpkin and Dess, 2004). An entirely new business dimension which may be referred to as the Net Economy has emerged (King et al., 2002; Kollmann, 2006). Internet-based ventures that are operating at this electronic trade level are based on innovative and promising online business models. In order to capture the value created in the Net Economy, new and highly adaptable $e$-entrepreneurs have emerged that generate revenue and profits independent from a physical value chain (Matlay and Westhead, 2005; Kollmann, 2006; Kollmann and Häsel, 2007).

At the same time, traditional SMEs operating at the physical trade level (which may be referred to as the Real Economy) increasingly utilise digital channels to improve their business processes and to reach new customer segments; therefore technological innovation and changes in customer behaviour are increasingly blurring the boundaries between Real and Net Economy. Considering the ongoing integration of online and offline business activities of both companies and individuals, enterprises operating at the physical and the electronic trade level need to approach each other. Integrated business concepts become a prerequisite for achieving customer loyalty (Amit and Zott, 2001; Porter, 2001; Levin et al., 2003). For many traditional SMEs and e-entrepreneurs, however, the requirements implicated by such strategies often go well beyond their means and competencies as they lack specialised marketing departments and large marketing budgets.

In this context, a collaborative interfirm integration of online and offline business models could represent a way of sustaining competitive advantage in spite of scarce resources. With the establishment of the Net Economy, the collaboration between enterprises has reached a new level of quality. The wide, open and cost-effective infrastructure of the internet allows a simple, fast exchange of data and thus a synchronisation of business processes over large distances. Particularly for e-entrepreneurs introducing new business ideas, online cooperation is a promising strategy as it enables the partners to create more attractive product offers and represents a 
basis for more efficiently and effectively communicating and distributing their product offers (Volkmann and Tokarski, 2006; Kollmann, 2006; Kollmann and Häsel, 2007). Also for SMEs operating in the Real Economy, cooperation has been of increasing significance in the past years. The presumable trigger for this is the intensification of competition that can be characterised by the globalisation of markets, the acceleration of technological development, the shortening of product life cycles and the increasing barriers for market entry. Especially within distribution channels, the functional performance of the channel members can be enhanced by cooperation incentives (Brassington and Pettitt, 1997).

Cooperation can be expected to hold a significant potential for the combined management of online and offline channels because the utilisation of the partner's existing channel infrastructure saves costs. Oftentimes, cooperation with partners that are specialised in specific channels is in fact the only way of implementing an own channel infrastructure. Partnering with e-entrepreneurs would help traditional SMEs to reach new market segments without extending themselves beyond their core competencies - and vice versa. Hence, companies may cooperate with a partner who has a complementary business model. In this context, Kollmann and Häsel (2006) define cross-channel cooperation as "the collaborative integration of online and offline business models aiming at attaining positive synergetic effects for the involved partners by a complement of competencies" (Figure 1).

Figure 1 Cross-channel cooperation between e-entrepreneurs and traditional SMEs

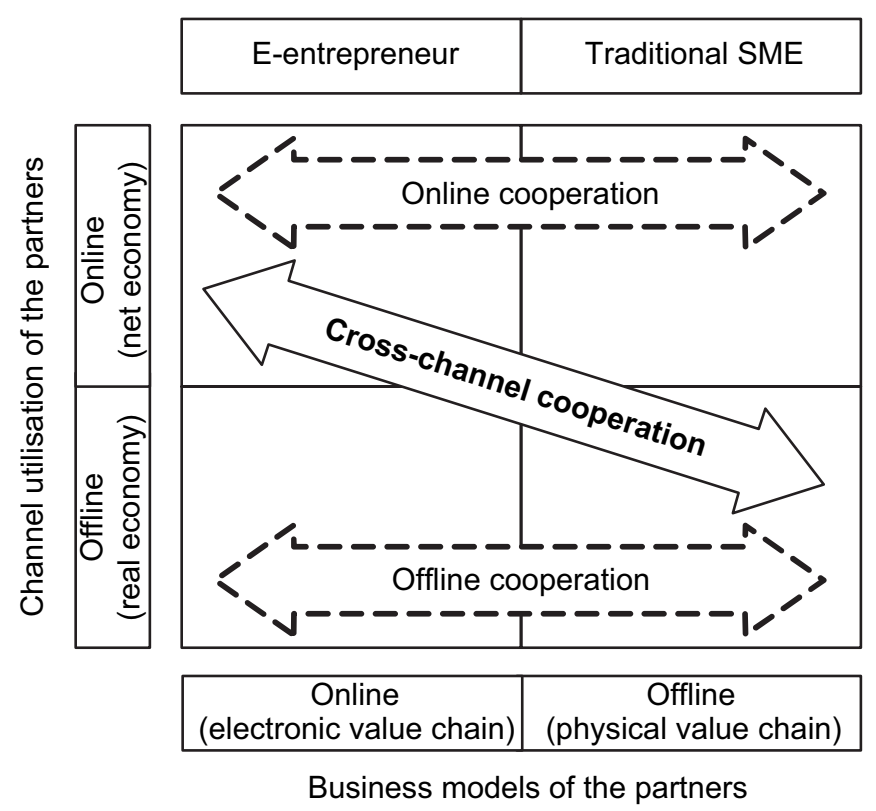

Although researchers have broadly covered the area of strategic cooperation, a comprehensive study on cooperation between e-entrepreneurs and traditional SMEs has not been undertaken until now. Indeed, we find that for such firms, cross-channel cooperation represents a new managerial task that is worthwhile to be examined in more detail. In particular, there are three main questions that arise: 
1 What are the motivations of e-entrepreneurs and traditional SMEs to cooperate with a complementary cross-channel partner?

2 Which forms of collaboration between e-entrepreneurs and traditional SMEs can be derived from these findings?

3 What are the basic rules of conduct for implementing collaborative cross-channel projects of e-entrepreneurs and traditional SMEs?

\section{Motivations for cross-channel cooperation}

In order to identify the motivations of e-entrepreneurs and traditional SMEs to cooperate with a partner having a complementary business model, an examination of both exogenous and endogenous factors influencing the partners' cooperation strategies seems to be reasonable. To explain why firms cooperate, two theoretical frameworks of strategic management, namely the market-based view and the resource-based view, have been widely applied and accepted in scientific literature. Consequently, the following considerations will build on these two theories.

\subsection{Exogenous factors: market-based view}

The market-based view is based on the assumption that the uniqueness and the success of firms are determined by their position in the market. In this sense, understanding the market makes up for the formulation of a successful competitive strategy. According to Porter's (1980) 'Five Forces' model, the competitive forces driving competition within a market include rivalry among existing competitors, bargaining power of suppliers, bargaining power of buyers, threat of substitute products and barriers to entry. Although deploying internet technologies implies several benefits for traditional firms (such as making information widely available and improving business processes), the internet also makes it more difficult to capture those benefits as profits because its net effect on the competitive forces is negative. This is what Porter (2001) calls the "great paradox of the Internet”. As they immediately relate to cross-channel strategies, three of Porter's (2001) findings shall be highlighted in this context: First, as online offerings are difficult to keep proprietary, the internet reduces differences between competitors and thus increases rivalry among them. Second, the establishment of online channels within an industry reduces switching costs and thus shifts bargaining power to end users. Third and finally, online channels represent a new substitution threat for nearly all kinds of offline channels. This is partly due to the fact that the internet at the same time provides communication, distribution and service functions and, thus, can be applied during the entire customer life cycle. In the music industry, for instance, the distribution of $m p 3$ files via the internet is threatening the distribution of compact discs via traditional retail stores.

Porter's (2001) findings go along with several changes in customer expectations and demands that can be observed over the last few years. These changes result from an increased need for individualisation, mobility, convenience and self-determination. Owing to the customers' increased bargaining power, their behaviour has changed. End users today use the internet and the real world complementarily; they browse in one channel and purchase in another, reflecting their goal to find the best selection, services 
and prices. For every buying decision, these hybrid customers assemble an individual channel mix for the respective presales, sales and after-sales phases of the customer life cycle. Customers even expect that they may choose which kind of channel to use to inform themselves about a product, to contact a retailer, or to buy or exchange a product.

Oftentimes, an individual buying decision involves channels of multiple competitors. For instance, customers inform themselves in a local bookstore (presales phase), but finally purchase the product at Amazon.com (sales phase). Consequently, in order to avoid customers switching over to the competition, enterprises need to adapt their channel portfolio in such a way that it covers the whole customer life cycle - anytime, anyplace.

Technological advances and changes in customer behaviour imply that cross-channel concepts will become a driving force in many industries. As a consequence of the benefits of online channels and the increasing stress of competition, many traditional firms have implemented clicks-and-mortar strategies that combine online and offline offers (Gulati and Garino, 2002; Müller-Lankenau and Wehmeyer, 2004). Actually, designing and implementing such a dedicated cross-channel strategy has become a key success factor for Real Economy firms, including SMEs (Madeja, 2005). Likewise, e-entrepreneurs need to build their strategy on new, hybrid value chains that bring together online and offline activities in unique configurations (Porter, 2001).

The market-based view shows that cross-channel concepts may often be a necessity to sustain competitive advantage. However, it does not fully explain the potential of collaborative approaches to implement such concepts. Also, a one-sided orientation towards static industries lacks a sound basis when considering the volatile environment of the Net Economy. Thus, "a definition of business in terms of what it is capable of doing may offer a more durable basis for a strategy than a definition based on the needs which the business is to satisfy" (Grant, 1991).

\subsection{Endogenous factors: resource-based view}

The Resource-Based View (RBV) of the firm focuses on the internal organisation of firms, which is, in particular, defined by their internal resources and capabilities (Prahalad and Hamel, 1990; Barney, 1991). RBV assumes that resources are heterogeneously distributed across firms and resource differences persist over time (Amit and Schoemaker, 1993; Wernerfeld, 1995). Hereon, researchers have theorised that when firms utilise resources that are valuable, rare, nonimitable and nonsubstitutable, they are able to achieve competitive advantage through strategies that cannot be easily duplicated by their competitors (Barney, 1991; Wernerfeld, 1995). According to RBV, cooperation results from the possibility of getting access to valuable resources and capabilities of the partner "that cannot be efficiently obtained through market exchanges" (Das and Teng, 2000). Similarly, hypothesising on the concept of core competencies introduced by Prahalad and Hamel (1990), it can be argued that cooperation should be built around a set of shared competencies that provide potential access to wide markets and make a significant contribution to the perceived customer benefits. Since building competencies is often difficult and expensive, firms should concentrate on their current core competencies while outsourcing certain tasks that others can handle better.

By nature, core competencies of Real and Net Economy firms are very different from each other. In that sense, one can identify a number of cases where unique capabilities of e-entrepreneurs and the specialised resources of traditional SMEs complement 
each other. These resource combinations may be referred to as cross-channel complementarities (Kollmann and Häsel, 2006). For instance, traditional firms are usually endued with a regional or national network of potential customers. Such a network can be utilised by an e-entrepreneur to balance its deficits in terms of market access and high customer acquisition costs (Baum et al., 2000). In return, e-entrepreneurs possess online distribution channels that are often based on existing partner networks (Volkmann and Tokarski, 2006).

When it comes to physical resources, SMEs operating at the physical trade level self-evidently lie ahead of their potential partners from the Net Economy. Real Economy firms are equipped with institutional channels such as stores that enable them to get in personal contact with their customers. Research suggests that such offline assets should be applied to complement online offerings, as "Customers who buy products over the Internet value the possibility of getting after-sales service offered through bricks-and-mortar retail outlets" (Amit and Zott, 2001). This could, for instance, include the possibility of exchanging a good that has been bought on an e-entrepreneur's internet platform.

Besides physical assets, a number of intangible resources may be of interest for the respective partner. When adding an online channel to their existing offline channel portfolio, traditional SMEs are often faced with quality shortcomings since the management of online channels requires very different skills (Webb, 2002; Müller-Lankenau and Wehmeyer, 2004). Cross-channel cooperation may avoid such shortcomings as e-entrepreneurs possess a significant expert knowledge in internet technologies and e-business strategies. In this regard, e-entrepreneurs can act as e-enablers that support the introduction of e-business in SMEs (e.g., the implementation of e-shop or e-procurement solutions). In addition, the complexity of a firm's channel portfolio increases exponentially with the integration of a new channel, because the service quality provided across channels must be kept consistent (Voss, 2004). In this context, cooperative arrangements with enterprises that are specialised on a specific kind of channel can help to control and utilise the quantity of channels available.

Intangible resources also include strategic assets such as brands (Amit and Schoemaker, 1993). Although mature Net Economy players such as $e$ Bay have often invested high amounts in building a brand, this is not true for e-entrepreneurs. Similarly, the corporate identity of young Net Economy firms is only marginally developed. In opposition to traditional SMEs, e-entrepreneurs also lack a pronounced buyer-seller trust. This results from an incertitude concerning the technology, and also from an incertitude concerning the transaction partner himself, who lacks a well-known brand and references. In this context, trust in a mature partner may compensate for missing experiences and information (Kollmann and Herr, 2005).

A combination of the market-based view and RBV appears to be a valuable instrument to explain the motivations for cross-channel cooperation, that is, the relationship between cross-channel cooperation and competitive advantage. However, the fact that internet-based resources are difficult to keep proprietary makes time an essential aspect of strategy and the duration of competitive advantage unpredictable (Porter, 2001). Hence, in industries that are highly influenced (or even created) by the emergence of online channels, where business models and the whole market structure are unclear, the challenge is not only achieving competitive advantage, but sustaining it (Eisenhardt and Martin, 2000). To explain how and why firms achieve competitive advantage in such industries, researchers have extended RBV (Teece et al., 1997). They underline that 
dynamic capabilities are a set of processes by which firms "integrate, reconfigure, build and release resources - to match and even create market change" (Eisenhardt and Martin, 2000). In the sense of cross-channel cooperation, these processes affect the external resources made accessible via the respective partners. Hence, it can be assumed that successful cross-channel cooperation processes represent dynamic capabilities that are a precondition to leverage a partner's resources to produce adaptive outcomes (Porter, 2001; Eisenhardt and Martin, 2000).

By nature, e-entrepreneurs can be expected to develop such capabilities more easily, as many business models in the Net Economy are explicitly built on collaboration (Volkmann and Tokarski, 2006). Also, ventures tend to have a higher learning and innovation capability than mature firms. In contrast, managers of traditional firms tend to have a lower ambiguity and risk tolerance and are often confronted with administrative barriers (Bhidé, 2000). This allows e-entrepreneurs to act with a higher degree of customer-focused innovation. Traditional SMEs should therefore regard e-entrepreneurs as flexible, compact business partners that are specialised in generating innovative ad hoc problem solutions, new approaches to marketing and additional customers. Yet traditional firms bring in most of the assets: brands, products, distribution and supplier networks, customer relationships and physical sites (Ernst et al., 2001).

The findings of this section are summarised in Figure 2. Building on the market-based view applied to explain the need for cross-channel strategies, RBV explains the benefits of implementing these strategies by collaborative means.

Figure 2 Motivations for cross-channel cooperation

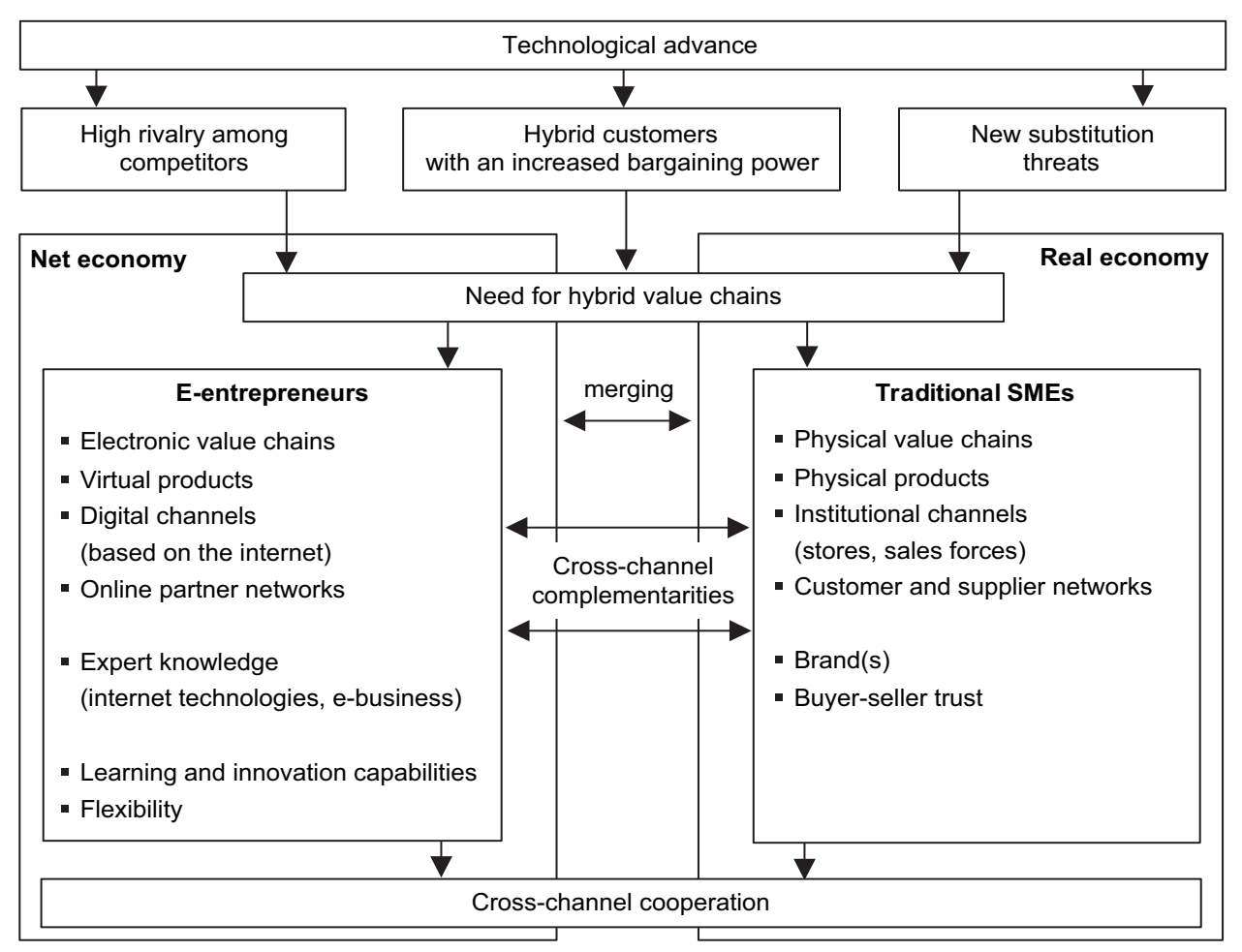




\section{Cooperation forms}

Cross-channel cooperation may leverage an e-entrepreneur's unique skills with the specialised resources of SMEs to create a more potent force in the marketplace. After having discussed the rationale behind cross-channel cooperation between e-entrepreneurs and traditional SMEs in the previous section, it is now possible to derive possible cooperation forms from these findings. In view of the above-mentioned cross-channel complementarities, it is reasonable to differentiate the resulting cooperation forms regarding the resources contributed by the partners; whereas less complex arrangements can be seen to involve rather loose resource pooling, more complex arrangements involve a true integration of the concerned resources and capabilities.

Besides resource contribution, forms of collaboration may also be differentiated regarding the channel functions they improve. In general, channels differ regarding their functional suitability for communication, distribution and customer service purposes. However, cooperation affects not only the corresponding presales, sales and after-sales phases of the customer life cycle, but also the product offer itself (Kollmann, 2006; Volkmann and Tokarski, 2006). Consequently, a classification based on the resulting benefits needs to include whether current offers are improved or new offers created.

In this context, we propose a classification of cooperation forms on two dimensions, shown in Figure 3. Building on the resource contribution (vertical axis) and the resulting benefits (horizontal axis), five subsets of cross-channel cooperation can be identified. These subsets are not intended to be seen exclusively; rather they are the constituents that make up an overall cooperative marketing strategy of the two partners. In practice, the partners will be confronted with hybrid cooperation forms, since cooperation usually aims at synergies resulting from more than one of the rather generic forms that will be discussed subsequently.

Figure 3 Classification of cross-channel cooperation forms

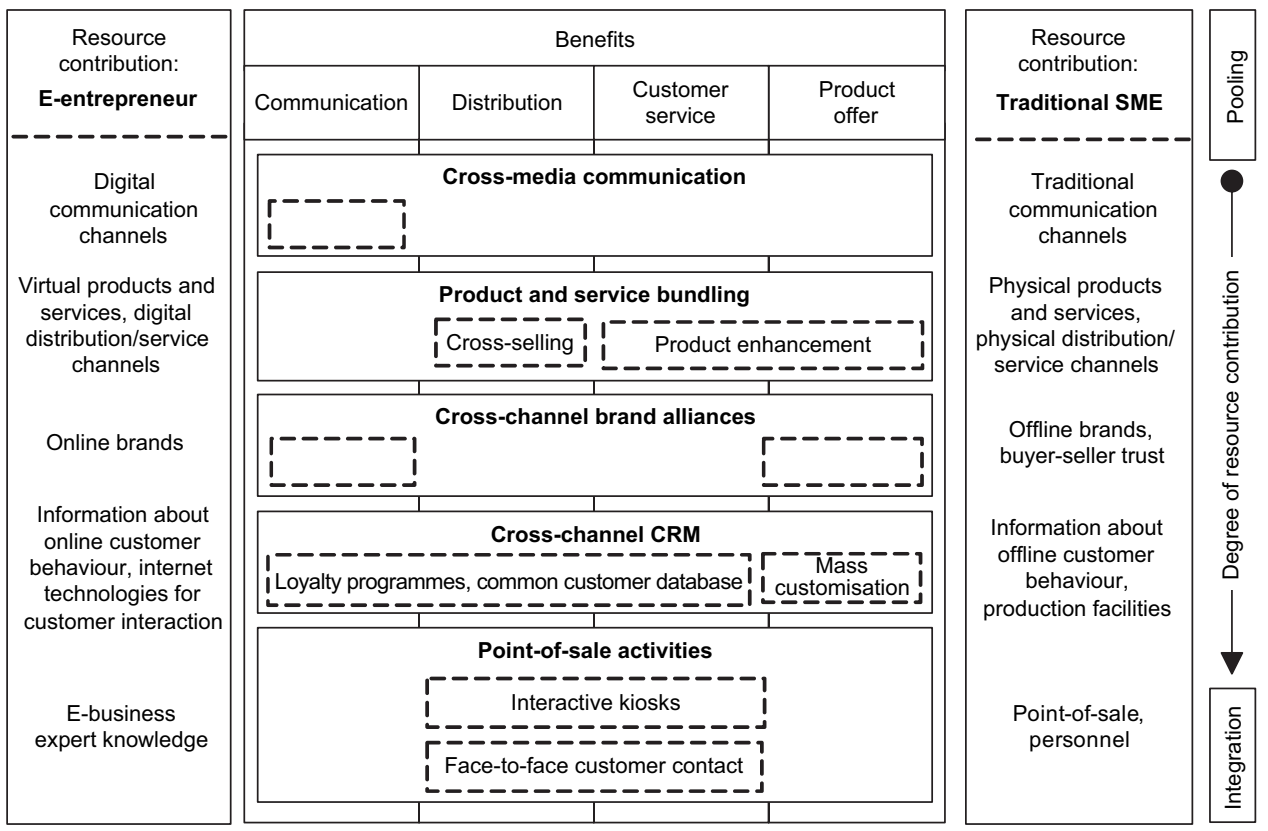




\subsection{Cross-media communication}

A strategic combination of online and print methods optimises advertising efforts. Online channels feature fast and comprehensive possibilities for customer interaction, whereas print media achieve attention and quicken interests (Jones and Spiegel, 2003). Obviously, an intensive cross-media communication integrating online and traditional media has significant advantages. When implementing such a strategy, the utilisation of the partner's channels is connected with substantially lower costs than the use of traditional mass media such as print media or television. Whereas the e-entrepreneur may profit from advertising spaces in mailings, on buildings and vehicles or in point-of-sale magazines of the offline partner, traditional SMEs may advertise on their partner's internet platform (Kruger and Fourie, 2003). Such arrangements can be seen as corresponding to a pure online cooperation, as in many cases SMEs also operate a website that banner advertisements may link to.

\subsection{Product and service bundling}

Whilst cross-media communication affects promotion, the focus is on product and place when bundling virtual and physical products and/or services. The objective behind such arrangements is the enhancement of the own offer to create a higher customer value. A product can be viewed at three levels: the 'core product', the 'actual product' and the 'augmented product' (Kotler, 2002). Customer value may already be increased by enhancing the actual product that is expected by the customer. For instance, an e-entrepreneur selling holiday trips on the internet may cooperate with a local car rental agency and thus allow customers to hire a car for the holiday resort in the same transaction. On the augmented product level, where competition is based on after-sales service, warranties and delivery, customer expectations may even be exceeded. For example, this would include establishing a new service channel that is set up on an existing channel made available by the respective partner (such as internet service portals or delivery services). In general, it is desirable for e-entrepreneurs to offer complementary goods that may not be directly related to the core transactions (Amit and Zott, 2001). The degree of product complementarity is determined by "the consumer's perception of the necessity of one product for the use of the second product" (Samu et al., 1999). In this regard, Amit and Zott (2001) differentiate between 'horizontal' (e.g., digital cameras and online photo development) and 'vertical' complementarities (e.g., e-payment and physical delivery) that may be provided by the partner and that enhance the value of the core product. However, one can also think of offering something completely unrelated, e.g., a voucher for a fast-food restaurant that is combined with an e-auction.

Whilst the first partner usually aims at enhancing his/her own core product, the second partner may aim at gaining access to additional distribution channels in order to reach customers that would be out of scope otherwise. Such cross-selling offers usually represent an independent service provided by the partner and aim at selling appropriate products to existing customers. Such strategies do not only improve the quality of customer-need satisfaction, but also result in quantitative aspects such as an increase in profitability and a reduction of costs. 


\subsection{Cross-channel brand alliances}

When introducing cross-channel product bundles, the brand image and publicity of both partners may be enhanced by featuring their brands together in the respective advertisements. Scholars have observed an overall elevation of the perceived quality when online and offline brands are aligned in such alliances (Levin et al., 2003).

Advertising alliances are especially important for new brands or established brands entering new markets. In both cases, they can be used to increase brand awareness and brand knowledge by leveraging the strengths of both partners and sharing costs (Samu et al., 1999). Thus, cross-channel brand alliances can be expected to be highly beneficial in one or both of the following cases:

- $\quad$ an e-entrepreneur partners with an established Real Economy brand to build a stronger offline market presence

- $\quad$ an SME wants to expand into an online market segment where it has a weak brand presence by partnering with a Net Economy partner that already serves that segment.

Researchers expect that "the future will see the establishment of more cross-channel brand alliances" (Levin et al., 2003). However, often it is two well-established brands that pool resources to co-brand with the idea that the bundled, new product can enjoy a unique positioning (Samu et al., 1999). This is possible for big players such as Amazon.com or eBay. For e-entrepreneurs and traditional SMEs that lack an established brand, such a strategy is out of the question. Cooperation strategies for e-entrepreneurs and SMEs therefore include one of the following (Samu et al., 1999):

- An entrepreneurial venture (i.e., a new brand) leverages the equity of its product or service by bundling with an established brand to establish preference for its core product. Research shows that these alliances are judged to be more favourable when the brands are seen as providing complementary features (as described above).

- The partners pool resources to develop a promotional cross-channel campaign featuring both brands. Such alliances do not require the product categories to be complementary; actually, this kind of alliance can even benefit from a noncomplementarity of the brands.

\subsection{Cross-channel CRM}

Developments in information technology have changed the manner in which competitive advantages are achieved today. The development of digital information channels in the framework of the Net Economy will further lead to the widespread economic use of information as a production factor (Weiber and Kollmann, 1998). Information about the customer influences the basic dimensions of the competitive advantage viewed from the standpoint of efficiency and effectiveness (Drucker, 1973; Day and Wensley, 1988).

Customer Relationship Management (CRM) can be understood as a revolving customer-interaction process during which firms generate, aggregate and analyse customer data, and employ the results for service and marketing activities (Seybold, 2001). CRM proves to be a key success factor in electronic business (Madeja, 2005). When collaborating in the area of CRM, online and offline partners may combine their information and knowledge resources. A common customer database that contains data 
from both the virtual and the real world may help to solve the overall 'customer puzzle' and support many operative and strategic decisions. The internet makes it easy to determine what users visit what sites and, thus, allows e-entrepreneurs to generate high-quality profiles in a short time that enable them to create an individually shaped relationship with their customers (Wiedmann et al., 2002). Conversely, for effectively collecting individualised customer data, traditional retailers need to overcome a media discontinuity between the physical and the virtual worlds. Loyalty programmes supported by plastic cards or coupons are a common method of enabling customer identification (Cortinas et al., 2005).

Maximising customer value implies that the customer becomes an integral part of the value-creating process and has a significant influence on it. On this basis, Pine et al. (1995) define the concept of mass customisation as follows: "Customisation means manufacturing a product or delivering a service in response to a particular customer's needs, and mass customisation means doing it in a cost-effective way." With the growing relevance of the internet, new potentials for mass customisation are made accessible. Partnering with e-entrepreneurs offers traditional SMEs a way of accessing these potentials. In order to achieve a permanent, individualised customer-problem solution with high customer value, a trilateral cooperation between the online partner, the offline partner and the customer is possible. Spreadshirt.net, for example, is an online merchandising company that allows people to design, buy and sell custom merchandise on the web. When the venture was launched by two German e-entrepreneurs in 2002, its initial strategy was grounded on cross-channel cooperation with two apparel printing companies from the Real Economy. Spreadshirt.net quickly became the leading provider of custom, online apparel in Europe and one of the most successful internet start-ups in recent years. As depicted in Figure 4, the customer contributes the information that is required to recognise and solve the problem in a market with fragmented demand, heterogeneous customer segments and short product life cycles. The e-entrepreneur contributes the internet technology that enables the customer to individually configure the physical product in an efficient way. The product or service is then produced and delivered by the Real Economy partner. Additionally, the partners may augment the product with an online and offline customer service. The objectives of such an agreement include economies of scale and - at the same time, in contrast to the originally exclusive standard strategies by Porter (1985) - the realisation of competitive advantages by diversification and the delivery of a higher customer value through individualisation.

\subsection{Point-of-sale activities}

Owing to the growing market concentration and internationalisation, as well as the growing relevance of mail-order distribution channels such as the internet or teleshopping, the point-of-sale is increasingly under stress of competition. As elaborated in Section 2, traditional retailers therefore implement clicks-and-mortar business models and utilise the interconnectivity of electronic markets to cross-market their products or services (Amit and Zott, 2001). This also includes the use of interactive kiosks, i.e., computer-like devices that enable retailers to leverage the power of the internet by providing cross-channel customer care capabilities and giving customers self-service access to products and services. Similarly, the deployment of interactive kiosks at the partner's point-of-sale can enable e-entrepreneurs to extend their websites to the physical store level. There, the e-entrepreneur's innovative services may represent an added value 
for the customer that can be leveraged by the offline partner. The cooperative utilisation of kiosk systems is thereby not necessarily limited to retailing industries: hotels, for example, could use kiosks to let guests not only check in or out of a room, but also check in for a flight via an associated internet platform.

Figure 4 A collaborative approach to mass customisation

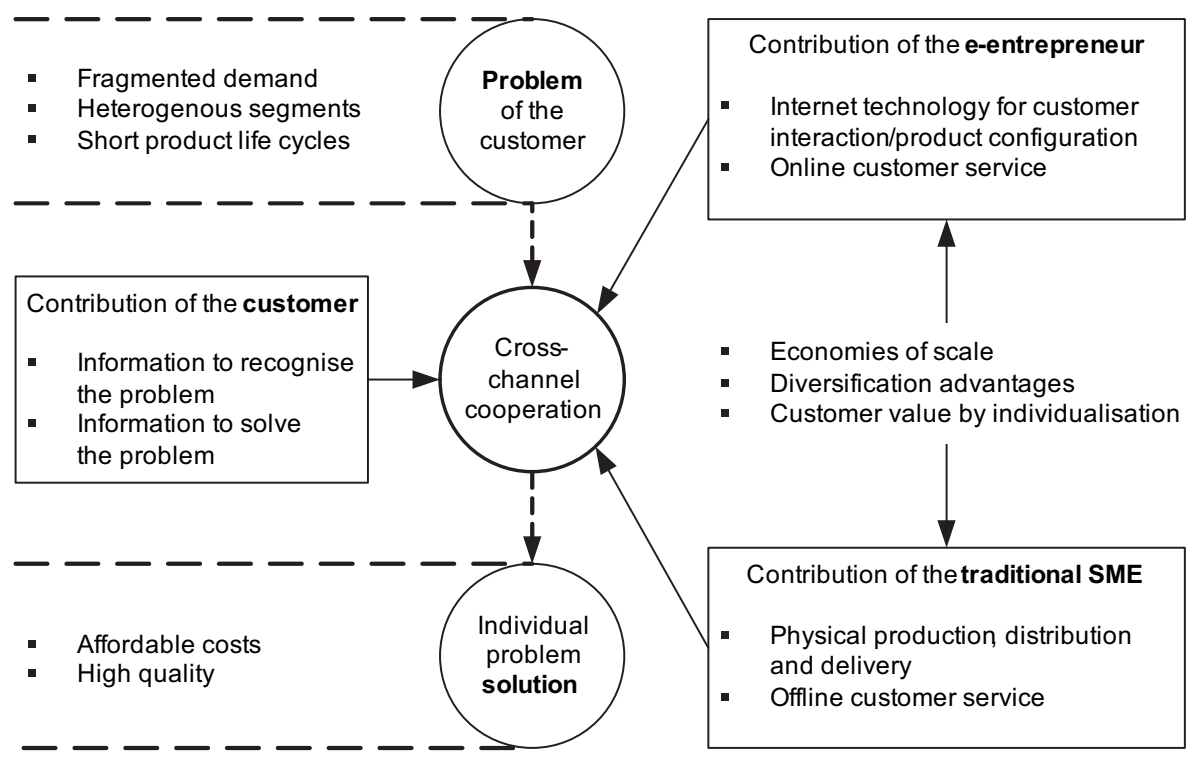

To overcome the above-mentioned media discontinuity, interactive kiosks are often used in conjunction with card-based loyalty programmes. Collaborative cross-channel loyalty programmes may include the possibility of point collection and redemption at the respective partner company, including electronic price discounts at in-store kiosks and printable web coupons that need to be delivered at the physical cash point. Similarly, the offline partner can give out 'e-coupons' with unique identification codes that the customer enters at the e-entrepreneur's virtual cash point.

In contrast to digital channels, institutional channels such as stores and sales forces enable traditional retailers to offer their customers personal support in face-to-face meetings. Consequently, the partner's point-of-sale may also be leveraged to offer face-to-face channel functions in the presales, sales and after-sales phase of an e-entrepreneur's customer life cycle, including hands-on experience when buying physical goods, personal consultation, repair services and exchange possibilities for goods that have been bought online.

\section{Implementing cross-channel cooperation projects}

Despite its potential value for e-entrepreneurs and traditional SMEs, cross-channel cooperation poses significant management challenges. As in marketing alliances in general, the potential for serious conflict and opportunism is high during the entire time of collaboration (Bucklin and Sengupta, 1993). Integrating very different business models and channel systems is inherently risky. These risks can be countered if both the partner 
identification and the following project execution are characterised by a systematic proceeding. Especially for young businesses, however, cooperation opportunities often result from existing personal contact networks, and the pressure of time and heavily stressed management resources may also result in a rather pragmatic proceeding. In many cases, entrepreneurs develop ad hoc strategies, anticipating or reacting to changes in the competitive environment. Whether strategy is planned or ad hoc, entrepreneurs and managers need to be sure whether their strategic objectives can be achieved with the help of cross-channel cooperation or not. Therefore, in our opinion, the following basic rules of conduct should not be neglected.

\title{
4.1 Strategic fit
}

Cross-channel cooperation can be seen as a form of 'working partnership', defined by Anderson and Narus (1990) as the "mutual recognition and understanding that the success of each firm depends in part on the other firm". The strategic fit is the prerequisite for a win-win situation and can only be ensured by the explicit formulation and communication of strategic objectives, as well as the pronounced engagement of both partners. "Trust and commitment are the building blocks of alliance effectiveness" (Perry et al., 2004). Conversely, during the 'dot-com boom', some cooperation agreements purely aimed at increasing the partners' reputation by brand alliances. However, "The days of the [...] press releases announcing, 'I love you, you love me, we're a happy family' are over" (Ernst et al., 2001). A missing fit between two brands, for instance, can cause dissonances that negatively affect the customer's brand attitudes. In their book on consumer behaviour, Hawkins et al. (2002) state:

\begin{abstract}
"Co-Branding has been shown to modify attitudes toward the participating brands. However, the effects can be positive or negative and can differ for the two brands involved. Thus, a firm considering co-branding should be sure that its target market views the potential partner positively and that the two brands fit together in a way that adds value."
\end{abstract}

This is confirmed in a study by Levin et al. (2003): Determining how alliances between online and offline brands impact brand images, they state that any online or offline firm should be cautious when forming an alliance since a partner brand of lesser quality could bring down its image. SMEs and e-entrepreneurs need to recognise such coherences and not reduce them to an aspect of marketing, since, especially in the Net Economy, the development of a brand has a highly strategic character and thus needs to be integrated into long-term strategy (Leitch and Richardson, 2003; Rubinstein and Griffiths, 2001).

The same is true for technology. It should be an enabler, but surely not the only reason for cooperative approaches. When implementing e-business concepts, traditional SMEs should first of all give an answer to the question 'why should we want to do this?' - which translates into 'is this appropriate for the characteristics of competition in our market and with our values and mission?' - before heading down a route that can be very dangerous (Ziliani and Bellini, 2004). SMEs, for instance, may explicitly aim at balancing nonavailable core competencies with those of an e-entrepreneur. Also, a common loyalty programme may fit perfectly into an SME's strategy to transform its traditional product- and purchasing-centred organisation into an information-intensive one. However, loyalty programmes in themselves of course do not turn SMEs into data-based, customer-driven organisations (Ziliani and Bellini, 2004). At the same time, 
SMEs need to prevent their businesses from arriving at a 'conditio sine qua non' in such cases. Methods of the portfolio theory can be applied to achieve a balanced ratio of partners and to determine whether a partner fits into the overall partnering strategy (Adobor and McMullen, 2002).

\subsection{Cultural and organisational issues}

Besides strategy, it is the organisational structure and the company culture of the partners that need to fit. "Partner match calls for the creation of alliances in which the chosen partners are similar in management style and company culture" (Bucklin and Sengupta, 1993). By nature, e-entrepreneurs are able to enter a cooperation agreement with each other more easily. Often the partners share similar visions, are more open-minded towards change and are able to find a common basis much faster. Although the informal company culture of Net Economy ventures can be regarded as one of their strengths, it also bears certain risks concerning collaboration with traditional firms that have complex hierarchies and a more formal company culture. These risks need to be limited from the very beginning. The partners need to develop a cultural awareness that can help to communicate and change the variety of implicit, cultural-specific misinterpretations. As Rayport and Sviokla (1994) put it "Managing in the marketspace requires a radical shift in thinking: from physical place to information space." It thus "clearly pays to develop prior relationships with prospective partners before engaging in formal alliances to ensure effective working relations" (Bucklin and Sengupta, 1993).

Besides the problems that may arise with respect to the coordination between the two partners, the integration of additional channels can lead to intracorporate conflicts that are likely to occur as a result of the increase in both amount and complexity of channels utilised. A channel conflict arises when a new channel is implemented at the cost of an existing channel without taking the respective organisational measures. In this case, personnel in charge of offline and online activities behave as competitors (Turban et al., 2006). The management ability to introduce change properly and the use of processes that support collaboration will determine the degree of collaboration between online and offline activities that are both internal and external to the firm.

\subsection{Power balance}

Bucklin and Sengupta (1993) suggest that "firms should build relationships with those having similar endowments in terms of resources, market positions, and competitive capabilities", as partners need to perceive and treat each other as equals. Power balance is "sought by the parties as the means to ensure that neither has the incentive to exploit the other". Since power imbalance is detrimental to alliance effectiveness, a firm would need to limit its choice to partners that are roughly similar in resources and market presence (Bucklin and Sengupta, 1993). More critically, such a guideline would deny the potential of otherwise desirable relationships between e-entrepreneurs and traditional SMEs.

Consequently, the partners need to mitigate the risks resulting from power imbalances, for example, by carefully drawing up a contract. Characteristics of cross-channel cooperation arrangements that help partners with unbalanced resource profiles and power positions to build fruitful alliances include termination penalties and exclusivity constraints that can be seen as pledges of commitment in the communication, distribution and service channels of the partner (Anderson and Weitz, 1992; Perry et al., 
2004). Financial incentives in the form of equity investments or direct monetary payments are the final component of the contract (Bucklin and Sengupta, 1993). Direct payments may be unidirectional or bidirectional and include both one-time fees and commissions on joint sales resulting from cross-channel product bundles, cross-selling or point-of-sale activities. Contracting is all the more important if a cross-channel cooperation strategy is connected with significant transaction-specific investments, as is the case, for example, for the deployment of interactive kiosks. In such complex projects, contractual terms effectively safeguard the partners' interests.

\section{Conclusion and outlook}

The pervasiveness of digital technologies and changes in customer behaviour are increasingly blurring the borders between electronic and physical trade levels. After going online in the last century using proprietary technologies that excluded other business areas, companies all over the world are now beginning to understand that the future of business-to-consumer electronic commerce is no longer limited to the customer's home PC, but can be found between the shelves of the supermarket next door. In order to be successful in the long run, both e-entrepreneurs and SMEs need to incorporate cross-channel concepts in their corporate strategies. The concepts presented in this paper highlighted that collaborative and integrative approaches enable firms to integrate online and offline business models without extending themselves beyond their means or competencies. It has been stated that cross-channel cooperation processes represent dynamic capabilities that contribute to sustainable competitive advantage by integrating highly complementary external resources. Building on resource contributions and resulting benefits, five generic forms of collaboration have been introduced. From a scholarly perspective, the framework presented in this paper may build a foundation for future empirical research on the benefits of cross-channel cooperation. From a practical point of view, this paper may assist entrepreneurs and SME managers in evaluating the benefits of cross-channel cooperation for their own business. It should have become apparent that creative projects between Real and Net Economy firms offer a wide range of opportunities and help to face up to a technological and societal development that is irresistible. However, despite the application of the rules of conduct mentioned in this article, a well-regulated project execution is quite implausible. Competition and strategic priorities are always subject to change in the Net Economy and characterise the evolutionary nature of young ventures. This results in an evolution of the cooperation itself. However, this evolution should not be seen as an indicator for strategic mistakes, but rather as a prerequisite for reaching the conjoint objectives (Doz, 1996). In fact, e-entrepreneurs and SME managers should approach partnerships dynamically as the long-term development of the cooperation is more important than the initial deal.

In the future, cross-channel cooperation can be expected to gain importance. With the proliferation of digital television and third-generation mobile technologies, novel and innovative online business models can be expected to emerge. Owing to the significance of internet-based technologies, the boundaries between mobile services and the 'stationary' web will increasingly become blurred. This will enable online business models to span multiple channels and become a pervasive part of daily life. Particularly in this context, the emergence of cross-channel cooperation can be expected: Will customers in the future browse web-based catalogues in order to create digital shopping 
lists that are then used with a mobile phone to guide the customer through the physical retail store? Similarly, television has begun to turn into an interactive online channel incorporating distribution and service potentials going much beyond spot advertisements. For e-entrepreneurs and SMEs having a partner that is specialised in a specific channel, tapping the full potentials of future developments will be much easier. To fully exploit these potentials, however, entrepreneurs and managers need to approach cross-channel cooperation in a systematic and precautionary way, based on sound strategy, and never as an end in itself.

\section{References}

Adobor, H. and McMullen, R.S. (2002) 'Strategic partnering in e-commerce: guidelines for managing alliances', Business Horizons, Vol. 45, No. 2, pp.67-76.

Amit, R. and Schoemaker, P. (1993) 'Strategic assets and organizational rent', Strategic Management Journal, Vol. 14, No. 1, pp.33-46.

Amit, R. and Zott, C. (2001) 'Value creation in e-business', Strategic Management Journal, Vol. 22, Nos. 6-7, pp.493-520.

Anderson, E. and Weitz, B. (1992) 'The use of pledges to build and sustain commitment in distribution channels', Journal of Marketing Research, Vol. 29, No. 1, pp.18-34.

Anderson, J.C. and Narus, J.A. (1990) 'A model of distributor firm and manufacturer firm working partnerships', Journal of Marketing, Vol. 54, No. 1, pp.52-58.

Barney, J.B. (1991) 'Firm resources and sustained competitive advantage', Journal of Management, Vol. 17, No. 1, pp.99-120.

Baum, J.A., Calabrese, T. and Silverman, B.S. (2000) 'Don't go it alone: alliance network composition and start-ups' performance in Canadian biotechnology', Strategic Management Journal, Vol. 21, No. 3, pp.267-294.

Bhidé, A. (2000) The Origin and Evolution of New Businesses, Oxford: Oxford University Press.

Brassington, F. and Pettitt, S. (1997) Principles of Marketing, London: Financial Times Management.

Bucklin, L.P. and Sengupta, S. (1993) 'Organizing successful co-marketing alliances', Journal of Marketing, Vol. 57, No. 4, pp.32-46.

Cortinas, M., Elorz, M. and Mugica, J.M. (2005) 'Loyalty cards: are retailers ignoring non-card-holder behaviour?', European Retail Digest, No. 45, pp.18-20.

Das, T.K. and Teng, B-S. (2000) 'A resource-based theory of strategic alliances', Journal of Management, Vol. 26, No. 1, pp.31-61.

Day, G.S. and Wensley, R. (1988) 'Assessing advantage - a framework for diagnosing competitive superiority', Journal of Marketing, Vol. 52, No. 2, pp.1-20.

Doz, Y.L. (1996) 'The evolution of cooperations in strategic alliances: initial conditions or learning processes?', Strategic Management Journal, Vol. 17, No. 1, pp.55-83.

Drucker, P.F. (1973) Management - Tasks, Responsibilities, Practices, New York: Harper \& Row.

Eisenhardt, K.M. and Martin, J.A. (2000) 'Dynamic capabilities: what are they?', Strategic Management Journal, Vol. 21, Nos. 10-11, pp.1105-1121.

Ernst, D., Halevy, T., Monier, J.H.J. and Sarrazin, H. (2001) 'A future for e-alliances', The McKinsey Quarterly 2001, No. 2, pp.92-102.

Grant, R.M. (1991) 'The resource-based theory of competitive advantage: implications for strategy formulation', California Management Review, Vol. 33, No. 3, pp.114-135.

Gulati, R. and Garino, J. (2002) 'Get the right mix of bricks \& clicks', Harvard Business Review, Vol. 78, No. 3, pp.107-114. 
Hawkins, D.I., Best, R.J. and Coney, K.A. (2002) Consumer Behavior: Building Market Strategy, Boston, MA: McGraw-Hill.

Jones, S.K. and Spiegel, T. (2003) Marketing Convergence: How the Leading Companies are Profiting from Integrating Online and Offline Marketing Strategies, Mason, MA: Thomson.

King, D., Lee, J., Warkentin, M. and Chung, H. (2002) Electronic Commerce: A Managerial Perspective, New Jersey: Pearson Education International.

Kollmann, T. (2006) 'What is e-entrepreneurship? - fundamentals of company founding in the Net Economy', Int. J. Technology Management, Vol. 33, No. 4, pp.322-340.

Kollmann, T. and Häsel, M. (2006) Cross-Channel Cooperation: The Bundling of Online and Offline Business Models, Wiesbaden, DUV.

Kollmann, T. and Häsel, M. (2007) 'Reverse auctions in the service sector: the case of LetsWorkIt.de', International Journal of E-Business Research, Vol. 3, No. 3, pp.57-73.

Kollmann, T. and Herr, C. (2005) 'Die Vertrauenswürdigkeit von jungen Unternehmen im elektronischen Handel', DBW - Die Betriebswirtschaft, Vol. 65, No. 2, pp.119-136.

Kotler, P. (2002) Marketing Management, Stuttgart: Prentice Hall.

Kruger, H. and Fourie, L.C.H. (2003) 'An investigation into the uniformity and nonuniformity of online/offline brand building in South Africa', South African Journal of Business Management, Vol. 34, No. 4.

Leitch, S. and Richardson, N. (2003) 'Corporate branding in the new economy', European Journal of Marketing, Vol. 37, Nos. 8-9, pp.1065-1079.

Levin, A.M., Levin, I.P. and Heath, C.E. (2003) 'Product category dependent consumer preferences for online and offline shopping features and their influence on multi-channel retail alliances', Journal of Electronic Commerce Research, Vol. 4, No. 3, pp.85-93.

Lumpkin, G.T. and Dess, G.G. (2004) 'E-business strategies and internet business models: how the internet adds value', Organizational Dynamics, Vol. 33, No. 2, pp.161-173.

Madeja, N. (2005) Corporate Success in Electronic Business: Results from an Empirical Investigation, Lohmar, Eul.

Matlay, H. and Westhead, P. (2005) 'Virtual teams and the rise of e-entrepreneurship in Europe', International Small Business Journal, Vol. 23, No. 3, pp.279-302.

Müller-Lankenau, C. and Wehmeyer, K. (2004) 'Mind the gaps - a model of web channel service quality in click \& mortar retailing', in S. Klein (Ed.) Relationships in Electronic Markets, Proceedings of the Eleventh Research Symposium on Emerging Electronic Markets, Dublin, Ireland, University College Dublin, pp.73-84.

Perry, M.L., Sengupta, S. and Krapfel, R. (2004) 'Effectiveness of horizontal strategic alliances in technologically uncertain environments: are trust and commitment enough?', Journal of Business Research, Vol. 57, No. 9, pp.951-956.

Pine, B.J., Peppers, D. and Rogers, M. (1995) 'Do you want to keep your customers forever?', Harvard Business Review, Vol. 73, No. 2, pp.103-114.

Porter, M.E. (1980) Competitive Strategy: Techniques for Analysing Industries and Competitors, London: Free Press.

Porter, M.E. (1985) Competitive Advantage: Creating and Sustaining Superior Performance, London: Free Press.

Porter, M.E. (2001) 'Strategy and the internet', Harvard Business Review, Vol. 79, No. 3, pp.62-78.

Prahalad, C.K. and Hamel, G. (1990) 'The core competence of the corporation', Harvard Business Review, Vol. 68, No. 3, pp.79-91.

Rayport, J.F. and Sviokla, J.J. (1994) 'Managing in the marketspace', Harvard Business Review, Vol. 72, No. 6, pp.141-150.

Rubinstein, H. and Griffiths, C. (2001) 'Branding matters more on the internet', Brand Management, Vol. 8, No. 6, pp.394-404. 
Samu, S., Krishnan, S. and Smith, R.E. (1999) 'Using advertising alliances for new product introduction: interactions between product complementarity and promotional strategies', Journal of Marketing, Vol. 63, No. 1, pp.57-74.

Seybold, P.B. (2001) The Customer Revolution, New York: Crown Publishers.

Teece, D.J., Pisano, G. and Shuen, A. (1997) 'Dynamic capabilities and strategic management', Strategic Management Journal, Vol. 18, No. 7, pp.509-633.

Turban, E., King, D., Viehland, D. and Lee, J. (2006) Electronic Commerce 2006: A Managerial Perspective, Upper Saddle River, New Jersey.

Volkmann, C. and Tokarski, K.O. (2006) 'Growth strategies for young e-ventures through structured collaboration', Int. J. Services Technology and Management, Vol. 7, No. 1, pp.68-84.

Voss, A. (2004) 'Taming the empowered customer: channel choice or channel behaviour?', in S. Klein (Ed.) Relationships in Electronic Markets, Proceedings of the Eleventh Research Symposium on Emerging Electronic Markets, Dublin, Ireland, University College Dublin, pp.66-72.

Webb, K.L. (2002) 'Managing channels of distribution in the age of electronic commerce', Industrial Marketing Management, Vol. 31, No. 2, pp.95-102.

Weiber, R. and Kollmann, T. (1998) 'Competitive advantages in virtual markets - perspectives of "information-based marketing" in the cyberspace', European Journal of Marketing, Vol. 32, Nos. 7-8, pp.603-615.

Wernerfeld, B. (1995) 'The resource-based view of the firm: ten years after', Strategic Management Journal, Vol. 16, No. 3, pp.171-174.

Wiedmann, K-P., Buxel, H. and Walsh, G. (2002) 'Customer profiling in e-commerce: methodological aspects and challenges', Journal of Database Marketing, Vol. 9, No. 2, pp.170-184.

Ziliani, C. and Bellini, S. (2004) 'From loyalty cards to micro-marketing strategies: where is Europe's retail industry heading?', Journal of Targeting, Measurement and Analysis for Marketing, Vol. 12, No. 3, pp.281-289. 